\title{
Investigating Factors That Influence the Growth of SMEs in Ghana: A Case Study of Makorla Market
}

\author{
Ebenezer Appiah $^{1}$, Evans Aidoo ${ }^{2}$ and Seth Larweh Kodjiku ${ }^{2}$ \\ ${ }^{1}$ Research Institute of Economics and Management, Southwestern University of Finance and Economics, \\ Chengdu, China \\ ${ }^{2}$ School of Information and Software Engineering, University of Electronic Science and \\ Technology of China, Chengdu, China
}

\begin{abstract}
It is an undisputable fact that SMEs are important to economic growth and are essential to generate employment. This study establishes the factors that influence the growth of SMEs in Ghana. The study adopted a factor analysis and linear regression methodology to analyze the data. The study employed the random sampling system. The study found out that, growths of SMEs are influenced by five major factors which are family factors, technological factors, experienced, location and human resource. Out of these five factors, three were significantly related to the growth of SMEs. These three factors are experience, human resource and technology. The study concluded that family, experience, location, technology and human resource are factors that influence the growth of SMEs in Ghana. The research therefore recommends that, the owners should take into consideration the training of employees, provision of incentives and also employ highly experienced personnel to manage the affairs of SMEs to improve upon their managerial skills thereby leading to the growth of the business.
\end{abstract}

Keywords: Small and Medium Scale Enterprises, Factor Analysis and Ghana

DOI: $10.7176 / \mathrm{EJBM} / 11-3-24$

\section{Introduction}

Small and Medium Enterprises (SMEs) play a significant role in all economies in the world, particularly to those in developing countries of which Ghana is no exception (Kayanula \& Quartey, 2000). The key roles help in activating and supporting economic growth and equitable development in both developed and developing countries. They add to the economic development of a country in different ways, by creating employment for the rural and urban labour force, by providing desirable sustainability and innovation in the economy as a whole. SMEs are important to economic growth and significantly key to generate employment (Harvie and Lee, 2005). $70 \%$ of new jobs creation in Southeast Asia are claimed to be coming from SMEs and in addition Harvie and Lee (2005) argue that SMEs contributed to more than half of the labour force within the private sector in the region. This is not so different in Ghana, as indicated by the Registrar-General; around 90\% of registered companies are SMEs, accounting for about $80 \%$ of the private sector and $92 \%$ of businesses in Ghana (Abor \& Beikpe, 2006). Villars (2010) additionally agreed to this reality through his studies where he indicated that SMEs contribute around 70\% to Ghana's Gross Domestic Product (GDP) and record for around 92\% of organizations in Ghana. Hence, there was a general consensus that the growth and survival of Small and Medium Size Enterprises (SMEs) is crucial for employment generation and poverty alleviation. For instance, Parker, Riopelle and Steel, (1995) found that SMEs on average employ about $15.5 \%$ of the labour force in Ghana. SMEs have over the years been very significant to the economic development of most developing countries, especially Ghana. Research done by Onugu (2005) on the growth and development of SMEs also showed that SMEs' growth and development depends predominantly on access to finance and firm size, ecological variables, for example, infrastructure, business legal status and legal registration.

However, Galindo and Schantiarelli (2003) indicated that in both developing and developed countries, SME's have less access to external financing, which lead SME's to be more restrained in their operations and growth as compared to that of large firms. In a recent study conducted by Beck et al. (2005) in developing countries, indicated that SMEs face greater financing obstacles than large firms do. Ayyagari et al., (2011) also portrayed that financing, crime, and political instability directly affect the rate of growth of SME's, with financing being the most significant constraint affecting small firms' growth. However, Rocha. et al (2010) analyzed the most binding constraint on firm growth in developing countries. Their findings demonstrated that each country faces a different set of constraints and that these constraints also vary by firm characteristics, especially firm size. In view of the above discussion, SMEs in Ghana have been seen to perform reasonably well and that they play a 
significant role in the growth and development of the country. Despite the vital role of SMEs in contributing significantly to economic growth and job creation, SMEs are facing more challenges around the world especially in developing countries (Bouazza, Ardjouman and Abada, 2015). Likewise, this sector continues to suffer massive neglect within the Ghanaian SMEs such as, lack of access to external financing, lack of technical knowhow, poor location, size of the firm, and low technological capacities. One may attribute some of the reasons to their size, access to finance, location and technological infrastructure and lack of available information or low level of education, among others. Hence, the present study undertaken seek to evaluate factors that influence the growth of SME's in considering their size, access to finance, location and technological infrastructure, lack of human resources and level of education.

\section{Review of Related Literature}

This section reviews related literature to the aforementioned topic. The section discusses reviews of existing theoretical and empirical literature relating to the study. The theoretical literature aspect of this paper basically focused on some factors that influence SME's growth. The empirical literature, on the other hand, provides previous research works or studies of other researchers that relate to the study.

\subsection{Factors that influence the growth of SME's in Ghana}

Motivation of the owner/manager and its influence on growth: Storey (1994) makes a distinction between positive and negative motivation. According to him, positive motivation includes the perception of market opportunities for a product or service and the desire to make money. Negative motivation encompasses dissatisfaction with an existing employer and threat of actual unemployment. Janssen (2002) supports the following: market opportunity, meeting a challenge, personal achievement, employment creation, independence, improvement of social status, profit, growth target.

Previous experience: Studies have generally found that SME owner/managers with more managerial, sector experience or prior SME experience as owner/manager tend to correlate with greater growth (Storey et al., 1989). A study carried out by Hall (2000) found that SME owner/managers in the UK with little experience at the start-up phase could have problems remaining solvent with an increase in expenditure in relation to their earnings. Kalleberg and Leicht (1991) their study found no relationship between prior SME experience and firm growth. Storey (1994) found reasonable evidence indicating a negative relationship between being unemployed before starting a business and subsequent business growth.

Firm size and its influence on growth: In relation to firm size, the general pattern is that smaller firms grow more rapidly than large ones (Storey, 1994; Delmar, 1997; Kumar, 1985). This view point has been rejected by a number of writers, for example Audretsch and Klepper (2000), Sutton (1997), Caves (1998). All note that a small firm has a lower likelihood of survival. This is supported by Westhead (1995) in his study of high technology firms in England, who found that larger firms have more propensities for growth than their smaller counterparts.

Human Resources Capacities: Human resources capacities form one of the most significant factors for the development of small firms. According to Hewitt and Wield (1992), firms with a skilled and well-educated workforce are probably to be more efficient. As noted by Lee (2001), human resource capacities form one of the most significant areas for the success of SMEs. Chandler and McEvoy (2000), indicate that human resource capacities have a positive effect on the growth of small firms, which increase employee skills and motivation, and eventually result in improving the productivity and long-term sustainability of small firms. Similarly, Batra and Tan (2003) note that a well-educated and skilled workforce has more learning and innovative abilities. However, various studies recognize low human resource capabilities as a major challenge for the development of SMEs in developing countries (Lee, 2001; Batra and Tan, 2003).

Technological Capacities: Drucker (1985) noted that new technologies improve efficiency, enable greater production, and are a source of profit for SMEs. According to Morse et al. (2007), technological capabilities benefit SMEs in several ways: they enhance SME efficiency, reduce costs, and broaden market share, both locally and globally. As noted by Lee (2001), a small business that adopts greater levels of technological sophistication can be expected to grow more rapidly than a similar firm that does not. Romijn (2001), and Yusuf et al. (2003) point out that low technological capabilities hinder and discourage SMEs from fully reaching their potential. Countries with high levels of technological growth tend to have high levels of entrepreneurial growth. From the above literature review, we conclude that the growth of SMEs is dependent on a range of internal and external factors. However, there is no clear understanding or specific theory as to whether an SMEs will sustain, 
grow, succeed, or fail. Scholars have put forward a number of factors concerning the important elements of the growing firm, such as Storey's (1994) identification of three necessary factors for growth: the entrepreneur, the firm, and strategy. However, there appears to be no unified pattern. Rather, the evidence points towards a complex set of interrelated factors that affect small business growth.

Managerial Capacities: Several studies have considered the management capacities of the top management team as key factors for small business growth. According to Olawale and Garwe (2010), management capacities are sets of knowledge, skills, and competencies that can make the small firm more efficient. Singh et al. (2008) emphasize that management skills are necessary for SMEs to survive and achieve growth. Aylin et al. (2013) state that management skills are a crucial factor for the growth of SMEs and that the lack of management skills is a barrier to growth and is one of the factors that can lead to failure. Pasanen (2007) suggests that the growth pattern of small firms is associated with their managerial capacities. Bhide (1996) notes that, a shortage of core competence and a skilled top management team is one of the main challenges faced by SMEs.

\subsection{Recent Empirical Reviews}

Sarwoko and Frisdiantara, (2016) investigated on the growth determinants of Small Medium Enterprises. The study empirically tested the three determinants of growth of small business namely; the individual factors, organizational factors and environmental factors. The study was conducted in Accra metropolis. They employed the purposive sampling techniques for the Analysis. They find out that, individual's factors directly affect the growth of the business, as well as an indirect effect through organizational factors.

Bouazza, Ardjouman and Abada, (2015) conducted a study on the topic "factors influencing the growth of small and Medium-Sized Enterprises" in Algeria. The study reveals that, the growth of SME's in Algeria is hampered by several factors that are beyond the SME's control and internal financing and human resource capacities.

Agyapong, Mmieh and Mordi (2018), investigated on the variables that influence the development of small and medium-sized enterprises (SMEs) with regards to Ghana, using business people (or owner/managers) of SMEs as the unit of examination. Thematic technique was used to analyze audiotaped interview transcripts. The result of the study depicted that several factors, including level of education, poor energy supply, access to external finance, competition, inflation and government policies influence the growth of SMEs in Ghana. They suggested that continued energy supply, review of lending and borrowing regulations, positive monetary policies, measures to battle unfortunate rivalry, provision of adequate training centers to prepare business people, and regulation on land acquisition ought to be government's need to guarantee steady development of SMEs in Ghana.

Banwo, Du and Onokala, (2017) also researched on the determinants of location specific choice: small and medium-sized enterprises in developing countries. The comparative study of Lagos and Zhenjiang coastal location reveals a myriad of contextual issues and location derived benefits arising from the nature of economic activity. Their strategic coastal domains revealed different levels of economic productivity, contextual issues and regulator-operator environment.

Most recently, Nyangala (2017) in the cause of examining the impacts influencing the growth of small and medium enterprises owned by youth in Nairobi. The study used a self-structured questionnaire in gathering data and employed the factor analysis method to analyzing the data through the Statistical Packages for Social Science (SPSS). The research uncovered that that access to finance, innovation, government policies and nonfinancial factors affect the growth of microenterprise. The study recommended that the government needs to creates avenues for youth learning on how to manage business efficiently.

\section{Study Methodology}

\subsection{Research Design}

The study adopted a descriptive research design in order for a thorough analysis of the topic. This method of research was utilized because data was easily collected and questionnaires were answered easily through the issuance of them. According to Mugenda (1999), descriptive research design determines and reports the way things are and also helps a researcher to describe a phenomenon in terms of attitude, values and characteristics.

\subsection{Population and Sample Size of the Study}

For this research, the target population is purposely, retail shops, workers and customers in the Greater Accra region. Data on the estimated total population of customers to the various retails shops was not readily available and was difficult to determine. For the aim of the study, 1,330 SME's were considered. Agyedu et al (2002) advised that the sample size must be 10 or 15 percent of the total population. Holding to this fact, the researchers used $15 \%$ of the targeted population. Thus, (15\% of 1330 which gave the researchers a sample size of 199.5 approximately 200 was the sample size utilized. Purposive sampling technique was used to select the 200 SMEs in Makorla market in Greater Accra Metropolis. 


\subsection{Data Source and Method of Data Collection}

The instrument employed for this study was a structured questionnaire. The questionnaire was the only instrument of data collection. The questions were largely closed- ended to make it simpler for the respondents and also for easy analysis. This technique involves the direct questioning of respondents regarding the relative evaluation of pre-specified attributes. In other words, respondents are requested to assess a set of retail shops in terms of given physical characteristics, such as location, size, population and design. McGoldrick and Thompson (1992) emphasized that many empirical studies have used structured scales or close-ended technique for appraising retail research hence, close-ended technique were finally chosen for the research. This questionnaire was constructed by the researcher and it was based on a 5 - point Likert scale ( $1=$ Strongly Disagree, $2=$ Disagree, 3 = Neutral, $4=$ Agree, and 5 = Strongly Agree)

\subsection{Methods of Data Analysis}

After the questionnaires were collected, the researchers categorized the data into demographics and specific questions that provide direct answers to the research questions. In order to ensure effective analysis and interpretation of the data, a factor specifically principal component (KMO) analysis and linear regression were used for presentation and analysis of the data gathered from the respondents. Predictive Analytical Software (PAS) version 21 was used to analyze and interpret the data collected from respondents. The analysis was done using the research objectives and the research questions as a measuring tool in order to realize the general objectives of the study. The results were discussed and summarized with some recommendations.

\subsection{Principal Component Analysis (PCA)}

It is a statistical procedure that uses an orthogonal transformation to convert a set of observations of possibly correlated variables into a set of values of linearly uncorrelated variables called principal components. The number of principal components is less than or equal to the number of original variables. This transformation is defined in such a way that the first principal component has the largest possible variance (that is, accounts for as much of the variability in the data as possible), and each succeeding component in turn has the highest variance possible under the constraint that it is orthogonal to the preceding components. The resulting vectors are an uncorrelated orthogonal basis set. The method of Principal Component Analysis (PCA) was used to establish the factors that may influence the growth of SMEs in Ghana. This research constructs a set of variables, COMP $i$ $(i=1,2,3 \ldots, k)$ out of a set of variables $\mathrm{Xj}_{j}(j=1,2,3 \ldots, k)$. The $C O M P i$ are simply linear combination of the $\mathrm{X}_{j}$ 's;

$$
\begin{aligned}
& C O M P_{1}=a_{11} X_{1}+a_{12} X_{2}+a_{13} X_{3}+\ldots \ldots \ldots . .+a_{1 k} X_{k} \\
& C O M P_{2}=a_{21} X_{1}+a_{22} X_{2}+a_{23} X_{3}+\ldots \ldots \ldots . .+a_{2 k} X_{k} \\
& C O M P_{1}=a_{31} X_{1}+a_{32} X_{2}+a_{33} X_{3}+\ldots \ldots \ldots . .+a_{3 k} X_{k} \\
& C O M P_{1}=a_{41} X_{1}+a_{42} X_{2}+a_{43} X_{3}+\ldots \ldots \ldots \ldots+a_{4 k} X_{k} \\
& \text { COMP }_{k}=a_{k 1} X_{1}+a_{k 2} X_{2}+a_{k 3} X_{3}+\ldots \ldots \ldots . .+a_{k k} X_{k}
\end{aligned}
$$

The $\mathrm{X}_{j}$ 's represents a set of 13 variables which are postulated to influence the growth of SMEs in Ghana. The alphas ( $a$ 's) known as the loadings are computed so that a respective principal component satisfies two conditions: i) the $C O M P_{i}$ are orthogonal and ii) the first principal component account for the maximum proportion of total variations in all $\mathrm{X}_{\mathrm{j}}$ 's. The second principal component absorbs the maximum of the remaining variations in the $X_{j}$ 's. The $X_{j}$ 's represents a set of 13 variables which are postulated to influence the growth of SMEs in Ghana. The alphas (a's) known as the loadings are computed so that the respective principal component satisfies two conditions: i) The COMPi are orthogonal and ii) the first principal component account for the maximum proportion of total variation in all the $\mathrm{X}_{\mathrm{j}}$ '. The second principal components absorb the maximum of the remaining variations in the $\mathrm{X}_{\mathrm{j}}$ 's. The $\mathrm{X}_{\mathrm{j}}{ }^{\prime} \mathrm{s}$ in this case are 13 variables (mainly influential factors and the reasons for growth) hypothesized to affect intention of factors influencing the growth SMEs in Ghana. A brief description of these variables is given below. 
Table 1: List of Variables (X's)

\begin{tabular}{c|c|l}
\hline No & Variable $\left(\mathrm{X}_{\mathrm{j}}\right.$ 's & \\
\hline 1 & $\mathrm{X}_{1}$ & My family borrows money from the business without paying \\
\hline 2 & $\mathrm{X}_{2}$ & I seldom change my line of work \\
\hline 4 & $\mathrm{X}_{3}$ & I use the internet and news to update myself on consumer taste and preferences \\
\hline 5 & $\mathrm{X}_{4}$ & I often use the social media as a medium to market my products \\
\hline 6 & $\mathrm{X}_{5}$ & The elements they offer to the customers are better than mine \\
\hline 7 & $\mathrm{X}_{6}$ & I accept and send money through mobile money services \\
\hline 8 & $\mathrm{X}_{7}$ & My family depends on me (business) \\
\hline 9 & $\mathrm{X}_{8}$ & My business has more market share in the market \\
\hline 10 & $\mathrm{X}_{9}$ & Positive words \& encouragement from others help keeps me moving \\
\hline 11 & $\mathrm{X}_{10}$ & Apart from the media, people update me on current issue \\
\hline 12 & $\mathrm{X}_{11}$ & My business is closer to suppliers \\
\hline 13 & $\mathrm{X}_{12}$ & My business is closer to raw material \\
\hline $50 u r c e$ & $\mathrm{X}_{13}$ & I have been in business for long \\
\hline
\end{tabular}

Source: Field data, 2018.

The task obtained the loadings, a's, which was transformed the Xj's into artificial orthogonal variable known as components. The next task was to test whether the component loadings were significant and subsequently decided how many principal components were to be retained in the analysis. After establishing the number of components to retain for the analysis, the study proceeds with the logistic regression of the factors that influence the growth of SMEs on the chosen principal components as follows;

\subsubsection{Computation of Component Loadings}

The loadings for the principal component, $(a$ 's), are obtained from a table of pairwise correlation of all the eleven $X_{j}$ variables using the formula;

$$
\mathrm{a}_{\mathrm{ij}}=\frac{\sum_{j}^{k} \rho_{\gamma i \gamma j}}{\sqrt{\sum_{j}^{k} \sum_{j}^{m} \rho_{\gamma i \gamma j}}}
$$

Where: $\rho \gamma_{i} \gamma_{j}$ represents the correlation coefficient between the $\gamma_{i}$ and $\gamma_{j}$ variables $\sum_{i}^{k} \sum_{j}^{m} \rho_{\gamma i \gamma j}$ represents the grand total of correlation coefficients across columns and rows of the correlation matrix. In this context, the loadings can be viewed as special forms of correlations among variables.

\subsubsection{Test of Significance of Component Loadings}

Numerous tests have been anticipated to test the significance of component loadings. The first is the "empirical test". This is a crude degree of significance of loadings. The rule of thumb with this approach is to consider factor loadings with absolute values of 0.45 or more as significant provided the number of observations exceeds 150 (Hair et al., 2012). The second test is based on the level of significance of the Pearson correlation coefficients since the factor loadings themselves are a form of correlation coefficients. Given that the sample for the study is 200 observations, the critical values of significant factor loadings are 0.15 at $5 \%$ level of significance and 0.255 at $1 \%$ level of significance. In this study, the empirical test threshold of 0.30 was employed in determining the significance of component loadings because the decision from this approach is consistent to that of the critical value of the correlation coefficient approach. 


\subsubsection{Criteria for Selecting the Principal Components}

A number of tests have emerged for selecting the ideal number of components in a PCA analysis. Two of them are discussed and used in this study. The first is the Kaiser (1958) criterion. The decision rule is to select only principal components with latent roots of eigen values greater than or equal to one. Let $\varphi_{m}$ be the $\gamma$ th eigen value of the $m$ th component computed as follows:

$$
\varphi_{m}=\sum_{i}^{k} a_{m i}^{2}
$$

Kaiser's criterion simply states that retain $C O M P_{i}$ if $\varphi_{m}>1$. The second approach to selecting the ideal number of components is the use of Carttell $(1966,2012)$ scree plot. This criterion is simply a plot of the latent roots against the order of extracted components. The shape of the resulting curve is used to decide on the number of components to retain. The decision rule is to retain components up to the point where the resulting curve has some curvature and reject components for which the plot becomes a straight line. In this study, both Kaiser (1958) and Carttell (1966) tests were employed to determine the ideal number of components.

\section{Empirical Results and Discussions}

\subsection{Socio-Economic Demographic Characteristics of Respondent's}

The general information of the respondents for the study comprised of their gender, their family type, their age, their type of SME, number of employees, their monthly average turnover and their level of education. The following are the results of the information. The socio-economic demographic characteristics of the respondents are summarized below;

\section{Gender of Respondents}

The researchers intended to identify the gender of respondents in the study. The findings presented in Table 4.1 indicated that, 87 of the respondents representing 50.9\% were females and 84 of the respondents representing 49.1\% were males. Thus, the findings indicated that, most of the respondents were female. This was not surprising to the researchers because, it is an underlying fact that, women dominate the market where goods and services are transacted for the past twenty-one (21) centauries as compared to men.

Table 2: Gender of Respondents

\begin{tabular}{l|l|c|c}
\hline \multicolumn{2}{|c|}{} & Frequency & \multicolumn{2}{c}{ Percent } \\
\hline & Male & 84 & 49.1 \\
\cline { 2 - 4 } & Female & 87 & 50.9 \\
\cline { 2 - 4 } & Total & 171 & 100.0 \\
\hline
\end{tabular}

Source: Researchers Field work

Age of the Respondents

The next demographic variable of the respondents examined was their age. However, researchers went on to identify the age bracket of the respondents in the study. The results presented in Table 4.2 below revealed that, $53.2 \%$ of the respondents were between the ages of 21 to 30 years, $25.1 \%$ were aged between 31 to 40 years, $9.4 \%$ were aged between 41 to 50 years old, $8.2 \%$ were below 20 years and $4.1 \%$ were 51 years and above. From the findings, it was indicated that greater proportion of the respondents fall within the age bracket of 20-30 years. This implies that, the population in Makorla market is highly concentrated with the youths. This however shows that the youths are more into the operation of Small and Medium scale Enterprises (SMEs) as compared to the middle and the aged people in Makorla market.

Table 3: Age distribution of respondents

\begin{tabular}{l|l|c|c}
\hline \multicolumn{2}{|l|}{} & Frequency & Percent \\
\hline \multirow{4}{*}{} & Less than 20 years & 14 & 8.2 \\
\cline { 2 - 4 } & 20-30 years & 91 & 25.2 \\
\cline { 2 - 4 } & 30-40 years & 43 & 9.4 \\
\cline { 2 - 4 } & 40-50 years & 16 & 4.1 \\
\hline & 51 and above & 7 & 100.0 \\
\cline { 2 - 4 } & Total & 171 & 25 \\
\hline
\end{tabular}

Source: Researchers Field work, 2018 


\section{Educational background of Respondents}

The researchers sought to find out the educational level of the respondents who participated in the study. The findings in Table 4.4 below established fact that $17.5 \%$ of the respondents had Basic and Middle school education, 28.1\% had Senior High school, 8.8\% had Higher National Diploma of education, 35.7\% had first degree and finally $9.9 \%$ had second $\left(2^{\text {nd }}\right)$ degree. Thus, the results indicate that majority of the respondents were significantly educated.

Figure 1: Educational Level of Respondents

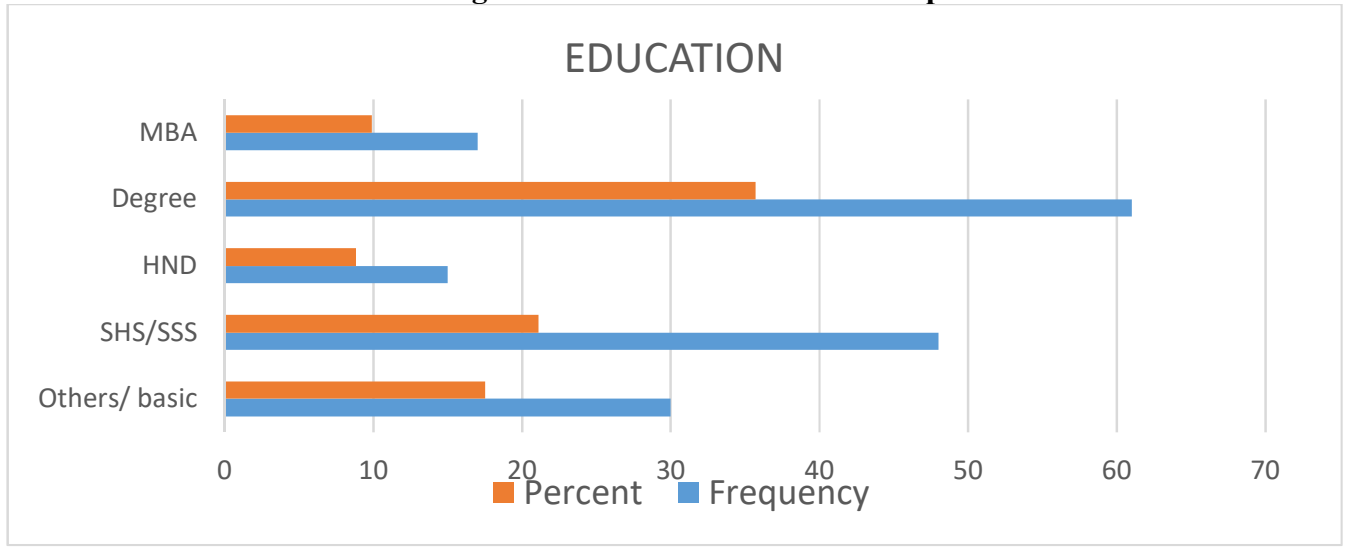

Family type of respondents

The analysis revealed that most of the respondents live in a nuclear family. specifically, the data shows that $71.3 \%$ of respondents are nuclear family members while $28.7 \%$ from extended family. However, it is so obvious to see a whooping respondent being members of the nuclear family since Ghanaians and Africans as a whole are yearning for western type of culture as far as family is concern. In this 21 st century, it is undisputable that, most people adopt the western way. Therefore, most of the respondent belongs to a nuclear family.

Table 4: Family size of Respondents

\begin{tabular}{l|l|c|c}
\hline \multicolumn{2}{|l|}{} & Frequency & Percent \\
\hline \multirow{2}{*}{} & Nuclear & 122 & 71.3 \\
\cline { 2 - 4 } & Extended & 49 & 28.7 \\
\cline { 2 - 4 } & Total & 171 & 100.0 \\
\hline
\end{tabular}

Source: Researchers Field work, 2018

Education by gender

According to the collected data based on education by gender, about $29 \%$ of the females have Senior High School (SHS) education as compared to the males who recorded about $19 \%$ of the same educational level. From this, it can be analyzed that, the females are more educated than males at this level. To speak of the next level of education which is the Higher National Diploma (HND), the males are leading with the rate of $10 \%$ and the females with $4 \%$ indicating that, the males are more in that educational level as compared to the females. Continuing with the Degree level of education, it is obvious that, the males records a higher rate of about $35 \%$ as compared to the females who have about $28 \%$. Moving on to the next level of education which is Master's degree (MBA), the chart shows that, more females turn to pursue their second degree as compared to the males with rates of about $9 \%$ and $8 \%$ respectively. Finally, 'Others' which denotes basic education has a significant proportion in the chart. About $20 \%$ of females at least have basic education as compared to the males who have about $10 \%$ of that same level of education. This indicates that, more of the market women in Makorla market have at least basic education as when it is match up with that of the males in Makorla market. 


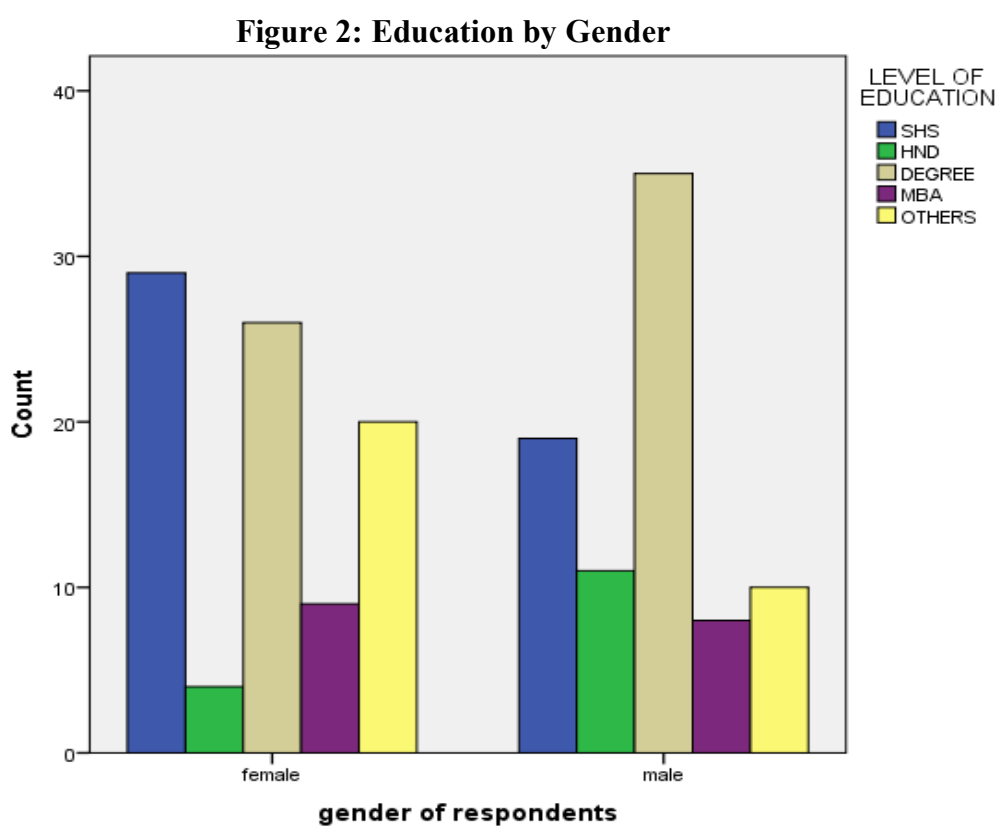

\subsection{The Un-rotated Component Table}

The table below shows a result of a transformation which leaves us with several cross loadings that makes a distinct interpretation of the five (5) components in the table nearly impossible. For instance, the third, fourth, fifth, seventh and eighth variables load onto components one (1) and two (2), and some components also share about three same variables. Due to this complexity faced in interpreting the table with cross loading, the study adopted rotation method in order to do away with the cross loadings. A significant majority of variable included in the study, loaded on either principal component land 2 with very few loadings onto the other three remaining components. This turnout of events blurred the distinction lines between the components therefore making interpretation very difficult.

Table 5: Component Matrix ${ }^{\mathrm{a}}$

\begin{tabular}{|c|c|c|c|c|c|}
\hline & \multicolumn{5}{|c|}{ Component } \\
\hline & 1 & 2 & 3 & 4 & 5 \\
\hline 1. My family borrows money from the business without & .707 & & & & \\
\hline 2. I seldom change my line of work & .690 & & & & \\
\hline 3. I use the internet and news to update myself on consumer & .682 & -.534 & & & \\
\hline $\begin{array}{l}\text { 4. I often use the social media as a medium to market my } \\
\text { products }\end{array}$ & .681 & -.470 & & & \\
\hline $\begin{array}{l}\text { 5. The elements they offer to the customers are better than } \\
\text { mine }\end{array}$ & .623 & & & & \\
\hline 6. I accept and send money through mobile money services & .578 & -.481 & & & \\
\hline 7. My family depends on me (business) & .539 & .468 & & & -.402 \\
\hline 8. My business has more market share in the market & .378 & .517 & & & .474 \\
\hline $\begin{array}{l}\text { 9. Positive words \& encouragement from others help keeps } \\
\text { me moving }\end{array}$ & & & .770 & & \\
\hline 10. Apart from the media, people update me on current issue & & & .671 & & \\
\hline 11. My business is closer to suppliers & .501 & & & .669 & \\
\hline 12. My business is closer to raw material & .507 & & & .663 & \\
\hline 13. I have been in business for long & .323 & .410 & & & 611 \\
\hline
\end{tabular}

Extraction Method: Principal Component Analysis. 


\subsection{The rotated Component Table}

The table below shows the result of DIRECT OBLIMIN Rotation. The major problem that was confronted with regards to the un-rotated factor matrix had been mitigated considerably. The rotation still maintains the five components with no cross loadings that will impair the naming of these components. However, the factor loadings had been spread relatively even over the various components than we had in the un-rotated matrix. These components have been named appropriately according to the various variables that load onto them. In view of the difficulty of the un-rotated factor matrix, a DIRECT OBLIMIN Rotation was applied to help deal with the problem of cross loadings. The result of this rotation is presented in the table below;

Table 6: Pattern Matrix ${ }^{\mathrm{a}}$

\begin{tabular}{|c|c|c|c|c|c|}
\hline & \multicolumn{5}{|c|}{ Component } \\
\hline & 1 & 2 & 3 & 4 & 5 \\
\hline 1. My family depends on me (business) & .843 & & & & \\
\hline 2. My family borrows money from the business without paying & .766 & & & & \\
\hline 3. I seldom change my line of work & .699 & & & & \\
\hline 4. The elements they offer to the customers are better than mine & .587 & & & & \\
\hline $\begin{array}{l}\text { 5. I use the internet and news to update myself on consumer taste } \\
\text { and preferences }\end{array}$ & & -.918 & & & \\
\hline 6. I often use the social media as a medium to market my products & & -.837 & & & \\
\hline 7. I accept and send money through mobile money services & & -.732 & & & \\
\hline $\begin{array}{l}\text { 8. Positive words \& encouragement from others help keeps me } \\
\text { moving }\end{array}$ & & & .781 & & \\
\hline 9. Apart from the media, people update me on current issue & & & .690 & & \\
\hline 10. My business is closer to suppliers & & & & .836 & \\
\hline $\begin{array}{l}\text { 11. My business is closer to raw material } \\
\text { 12. I have been in business for long }\end{array}$ & & & & .825 & 852 \\
\hline 13. My business has more market share in the market & & & & & .792 \\
\hline
\end{tabular}

Rotation Method: Oblimin with Kaiser Normalization.

Table 7: Naming the principal component

\begin{tabular}{|l|l|}
\hline PRINCIPAL COMPONENT & NAME \\
\hline 1. & Family factor \\
\hline 2. & Technological factor \\
\hline 3. & Human resource factor \\
\hline 4. & Location factor \\
\hline 5. & Experience factor \\
\hline
\end{tabular}

\section{Component 1; Family Factor}

The first principal component is named Family. This component has an Eigen value of 3.682 accounted for $28.321 \%$ of total variations in the variables. This component has four variables loading onto the component significantly. Collectively, the variable focused on family dependency. Families serve as great support to all of us one way or the other. Formation of businesses (SME) starts from idea generation, nursing those ideas through to the stage where the firms come into existence. At this stage, families play roles such as advice, financial support, labour and sometimes words of encouragements just to keep the business going. Families play integral part as far as formation of SMEs is concerned.

Family support alone can encourage a risk adverse person to take risk by investing his or her savings as capital into the proposed firm whose future is yet not known. Some families show up to help as employees without or little reward. All this is done just to help the infant firm grow. Members of some families offer help in terms of 
labour just for the owner to save and plough back the labour cost into the firm. It is however effective and advantageous to owners who belong to an extended family.

Looking at the other side of family component, SMEs face great challenge of lending fund of the business to some members of the family without them paying back, drawing for personal and family use, and spending the profit made from the firm on the family, if the owner is the bread winner of the family. Most SME owners turn to use their profit to fend for their family instead of re-investing to boost the business so as to yield more revenue or returns. Great dependency of families on SMEs poses a threat for the business's survival. It's an undeniable fact that business owners from extended families who are bread winners faces slow or no growth in their business. When this occurs, the firm is unable to cover both fixed and variable cost; consequently, the firm must shut down in order not to run into bankruptcy. In conclusion, firms find it difficult to grow and progress because members of the family highly depend on the business for living or survival. SMEs can only overcome these problems when they treat firm separately form themselves. As stated in the business entity concept "personal transactions of owners are treated separately from that of the business"

Component 2; Technological Factor

The second principal component that may affect the factors that influence the growth of SMEs in Ghana specifically Makorla market is labeled as Technological factor. This principal component has an eigenvalue of 1.624 and account for about $12.496 \%$ of total variations in all the variables. The component has three variables significantly onto it in the rotated component table. The variable focused on technological reasons that may compel the growth of SMEs. Technology have come a long way to help accelerate and promote quality and a faster way of doing things to be effective and efficient in their dealings. Technological advancement benefits SMEs by connecting them to a wide range of information. SMEs can gain access to information through mediums such as the internet, social media, even on the news broadcast. This gives them an upper hand by adjusting to the taste and preference of consumers and also improves upon their product. Thus, re-branding, adding more value and improve packaging of the product.

Technology also benefit SMEs by connecting them world-wide in order to market their products to the world at large. Contrary to that, SMEs which fail to update themselves technology wise, lack behind in the competitive market. The findings concluded that, SMEs may want to be a part of the technological world in order to stand up to competition level in the market. This problem has caused many SMEs specifically micro to run out of business. The problem of technological advancement is one of the reasons for many SMEs in Ghana, specifically Makorla market are not progressing. Catching up with technological and adjusting to it will help solve the problem stated above.

Component 3; Human Resource Factor

Human resource happens to be the third principal component that may also affect the factors that influence the growth of SME's in Ghana specifically the Makorla market. This principal component has an eigenvalue of 1.279 and accounts for $9.836 \%$ of total variations in all the variables. The component has three variables that focus on the usefulness of resources which may one way or the other compel the growth of SME's in Ghana. The relevance of being motivated by people or customers is that it encourages traders or service providers to help build an attitude of developing positive relationship even with people they are not familiar with. A habitual practice of this will help increase customer base which may lead to profit maximization and in the long run the growth of the SME. Consequently, access to information through the people, sellers or service providers know personally also aid in the growth of SME in Ghana. This becomes possible due to decisions traders may take based on the information given to them. Information will help them increase or decrease the prices of products or services they offer customers so as to help curb problems of loss or to increase revenue.

Component 4; Location Factor

This principal component had an eigenvalue of 1.148 out of the total of all components, $8.828 \%$ of total variations in all the variables. The component has two variables that focused on Location issues. The distance from work or place of operation which universally constitute to location is the principal reason why SMEs in Ghana, specifically Makorla market may not experience growth. The second reason why SMEs may not experience and enjoy growth is how far they live from their suppliers. The longer the distance, the higher the transportation cost incurred by the supplier which is then factored in the selling price. This means, a higher transportation cost by both supplier and where raw materials are conveyed are shifted to the firms. This goes a long way to increase the cost of production and when cost of production shoots up, their price quote on the proposed product will be high. Meaning, the cost has been transferred to consumer. This makes the product in question unattractive to customers or final consumers, as stated in an economics law that "all other things being equal, the higher the price the lower the quantity demanded and the lower the price the higher the quantity 
demanded. As a result, the demand for that particular product will fall and less or no profit will be enjoyed by the firm.

Hence, the business or the firm becomes unattractive for prospective foreign investors to invest in. The location problem above should be taken into consideration whenever SMEs are setting up their firms. Location is a major key player as far as growth of businesses is concerned. A strategic and a catchy location will attract more customers to the firm. Also, the nearness of firms to raw materials and suppliers makes it easy and convenient for the delivery of inputs at a relatively lower cost. This goes a long way to reflect in the pricing of the product. Eventually, demand for the product will increase leading to higher profit margin or increase in revenue which turn to attract investors to invest in the firm, hence growth is seen or experienced. To conclude with, SMEs are to take location as a strong and serious factor when setting up firms.

Component 5; Experience Factor

The final reason why SME's will enjoy growth may be based on how experience its owners or people working within them are. This principal component has an eigenvalue of 1.052 and accounts for $8.095 \%$ of total variations in all variables. Experience as a component has two factors which are; the number of share the product has in the market and the number of years one has been in business. A trader or service provider who has been in business for a very longer period will be privileged to learn more and also get him or herself familiar with things he or she did not know when he started business. On the other hand, a trader or service provider working in an enterprise is bound to be less experience when he or she spends only fewer years in his field of work.

The Influence of Growth Factors on the Variables

\begin{tabular}{|ccccc|}
\hline Variables & $\begin{array}{c}\text { GRTH } \\
\text { FACTOR } ~\end{array}$ & $\begin{array}{c}\text { GRTH } \\
\text { FACTOR 2 }\end{array}$ & $\begin{array}{c}\text { GRTH } \\
\text { FACTOR 3 }\end{array}$ & $\begin{array}{c}\text { GRTH } \\
\text { FACTOR 4 }\end{array}$ \\
\hline Family & -0.53 & 0.042 & 0.053 & 0.044 \\
& $(0.519)$ & $(0.250)$ & $(0.538)$ & $(0.593)$ \\
Technology & 0.80 & 0.076 & -0.063 & $-0.171^{* *}$ \\
& $(0.313)$ & $(0.327)$ & $(0.443)$ & $(0.034)$ \\
Human resource & $0.150^{* *}$ & $0.287^{* * *}$ & 0.072 & 0.049 \\
& $(0.045)$ & $(0.000)$ & $(0.355)$ & $(0.515)$ \\
Location & 0.074 & 0.048 & -0.025 & 0.038 \\
& $(0.346)$ & $(0.531)$ & $(0.756)$ & $(0.633)$ \\
Experience & $0.219 * * *$ & $0.241^{* * *}$ & 0.038 & $0.131^{*}$ \\
& $(0.005)$ & $(0.002)$ & $(0.635)$ & $(0.097)$ \\
Constant & 3.81 & 3.784 & 3.982 & 3.971 \\
\hline No_of observation & 170 & 170 & 170 & 170 \\
F-Value & 3.027 & 5.423 & 0.533 & 2.469 \\
& $(0.012)$ & $(0.00)$ & $(0.751)$ & $(0.035)$ \\
R & 0.084 & 0.141 & 0.016 & 0.070 \\
Adj. R2 & 0.056 & 0.115 & -0.014 & 0.041 \\
\hline
\end{tabular}

From the table above, the study throws more light on the relationship that exists between the established factors and five different measures of growth. These five measures reflect the extent to which the SMEs have experienced growth in different aspects of their operations. Growth factor 1 shows the detent to which revenue of the firm has increased over the past year. Growth factor 2 shows the extent to which the market share of the SMEs under consideration has increased over the past year. Growth factor 3 shows the extent to which the customer base has increased. Finally, growth factor four shows the extent to which production output of the SMEs has increased over the past year.

The results show that, there are three variables that can be said to have significant influence on the growth of SMEs in Ghana starting from the most important variable. For experience (EXP), a unit increase in experience will lead to a relative increase in growth factor 1(revenue) and 2(market shares) by 0.219 and 0.241 respectively. For HR, a unit increase in human resource will cause growth factor 1(revenue) and growth factor 2 (market shares) to increase by 0.150 and 0.287 respectively. Last variable which is TECH and a percentage increase in technology will lead to a relative decrease in growth factor 4 by 0.171 . 
From the regression table above, the research shows that experience and human resource are the most influential variables at $1 \%$ level of significance. From this result one can conclude that growth of SME's is most influenced by the level of experience the owner of the enterprise and the human resources he/she employs in running the business. The model found a statistically significant positive relationship between human resource management and growth of SMEs (Factor 1) at a 5\% level of significance. A negative relationship was found between technology and growth in relation to factor 4. It can therefore be concluded that the variables EXP, HR and TECH do influence the growth of SME's. The higher the level of experience the owner of the enterprise has the higher the probability of growth of the SME, and the more human resource it employs the higher SMEs grow in terms of market shares. The regression diagnostics show that the combined explanatory power of the model, as depicted by the F-Statistics, is significant in three of the four regressions. The coefficients in all models of growth, with the exception of growth in Customer Base model, are jointly significant in explaining growth rates of SMEs.

\section{Conclusion and Policy Recommendations}

The analysis of the study was exclusively conducted on two frontiers. First, the study employed the method of principal components to examine the latent factors that influence the growth of SMEs. Secondly, the study uses regression analysis to rank and find out the level of influence of the said factors on the growth of SMEs in Ghana. Data was collected from a sample of 200 using questionnaires and 171 were returned. Most researchers wrote on SMEs but fail to examine main factors that influence the growth of SMEs. This is to say that this study is unique even though there are similar literatures on it. SMEs in Ghana are influenced by five key latent variables. Firstly, potential SMEs considered the advantageous influence that family as a factor will have on their business as compared to disadvantageous influences. Secondly, SMEs that turned to employ high level of technology which comes at a higher cost (installation cost, maintenance cost, and cost of hiring skilled or technical personnel) and also the phobia faced by owners bring about a negative relationship between technology and growth in a short run. In view of this, a percentage increase in technology thus employing more technological factor will lead to a decrease in growth of the enterprise. This cannot be said in the case of a longrun simply because it is assumed that, all things being equal in the long run (decades to come) both employers and employees will catch up with technology and find it confortable working with high tech equipment that will boost output and hence growth is seen. In addition, labour force of SMEs which form human resource factor also influence the growth of SMEs. From the findings, firm's geographical location where the operations of the business are carried on has a proportion of influence on the growth of SMEs in Ghana "Makorla market" Finally, prospect SMEs consider the influence that experience as a factor will have on their business. The relationship of experience which is a positive one creates a clear conclusion that, firms must gain some level of experience in other to succeed in terms of growth thus "how long an SME has been in business" influences SME growth.

With reference to the analysis of principal component, the study found out that, growths of SMEs are influenced by five major factors which are family factors, technological factors, experienced, location and human resource. These assertions are based on evidence from the analysis. This implies that, among the five factors spelt out using principal component the study ranked the factors that most influence growth of SMEs in Ghana as Experience, Human Resource and Technology respectively. Based on the analysis and findings of the study, the study that Government agencies and private individuals who are willing to go into partnership with these SMEs should consider training of their human resource (its owners and employees). Since SMEs face the fear of using technological equipment in the operation of their day-to-day transaction due to unfamiliarity, the Government, NGOs and interested companies and individuals who are technologically inclined, can educate them on the large positive impact that technology can make on their enterprise at the long run through organization of practical workshops. The study finally recommends that owners of SMEs should take it upon themselves in treating their businesses separately from their own personal operations as far as family is one of the variables that influence the growth of SMEs is concerned.

\section{References}

Abor, J. Biekpe, N. (2006), 'How are SMEs financed? Evidence from the Ghanaian non-traditional export sector' Environmental and Planning C: Govt and Policy, 24, 71-81

Agyedu, G.D., Donkor, F. and Obeng, S. (2007). Teach Yourself Research Methods, University of Education, Winneba, Accra.

Amal, M., \& Rocha Freitag Filho, A. (2010). Internationalization of small-and medium-sized enterprises: a multi case study. European Business Review, 22(6), 608-623. 
Ates, A., Garengo, P., Cocca, P., \& Bititci, U. (2013). The development of SME managerial practice for effective performance management. Journal of Small Business and Enterprise Development, 20(1), 2854.

Audretsch, D., \& Klepper, S. (2000). Innovation, evolution of industry and economic growth. Edward Elgar Publishing.

Ayyagari., Meghana., Asli Demirgüç-Kunt and Vojislav Maksimovic (2011), "How Important Are Financing Constraints? The Role of Finance in the Business Environment”, World Bank Policy Research Working Paper, No. 3820

Banwo, A. O., Du, J., \& Onokala, U. (2017). The determinants of location specific choice: small and mediumsized enterprises in developing countries. Journal of Global Entrepreneurship Research, 7(1), 16.

Batra Geeta and Tan Hong (2003), SME Technical Efficiency and Its Correlates: Cross-National Evidence and Policy Implications, World Bank Institute Working Paper.Info. worldbank.org/etools/docs/ [Accessed on April 8, 2014].

Beck, T., Demirgüç-Kunt, A. S. L. I., \& Maksimovic, V. (2005). Financial and legal constraints to growth: Does firm size matter? The Journal of Finance,60(1), 137-177.

Bhoyar, R. V., Titus, S. K., Bhide, A. D., \& Khanna, P. (1996). Municipal and industrial solid waste management in India. Journal of IAEM, 23, 53-64.

Bouazza, A. M., Ardjouman, D., \& Abada, O. (2015). Establishing the Factors Affecting the Growth of Small and Medium-sized Enterprises in Algeria. American International Journal of Social Science, 4(2), 101121.

Camisón, C., \& Villar-López, A. (2010). Effect of SMEs' international experience on foreign intensity and economic performance: The mediating role of internationally exploitable assets and competitive strategy. Journal of Small Business Management, 48(2), 116-151.

Cattell, R. (Ed.). (2012). The scientific use of factor analysis in behavioral and life sciences. Springer Science \& Business Media.

Cattell, R. B. (1966). The screen test for the number of factors. Multivariate behavioral research, 1(2), 245-276.

Caves, R. E. (1998). Industrial organization and new findings on the turnover and mobility of firms. Journal of economic literature, 36(4), 1947-1982.

Chandler, G. N., \& McEvoy, G. M. (2000). Human resource management, TQM, and firm performance in small and medium-size enterprises. Entrepreneurship Theory and Practice, 25(1), 43-58.

Davidsson, P., \& Delmar, F. (1997). High-growth firms: characteristics, job contribution and method observations.

Drucker, P. F. (1985). Entrepreneurial strategies. California Management Review, 27(2).

Eng, Q. E., \& Yusof, S. R. M. (2003). A survey of TQM practices in the Malaysian electrical and electronic industry. Total Quality Management and Business Excellence, 14, 63-78.

Galindo, A. J., \& Schiantarelli, F. (Eds.). (2003). Credit constraints and investment in Latin America. IDB.

Hair, J. F., Sarstedt, M., Ringle, C. M., \& Mena, J. A. (2012). An assessment of the use of partial least squares structural equation modeling in marketing research. Journal of the academy of marketing science, 40(3), 414-433.

Hall, G., Hutchinson, P., \& Michaelas, N. (2000). Industry effects on the determinants of unquoted SMEs' capital structure. International journal of the economics of business, 7(3), 297-312.

Harvie, C., \& Lee, B. C. (Eds.). (2005). Sustaining growth and performance in East Asia: The role of small and medium sized enterprises (Vol. 3). Edward Elgar Publishing.

Henry, N. A. (2017). Factors affecting growth of small and medium enterprises Owned by the youth in Nairobi.

Hewitt T. and D. Wield (1992), "Technology and Industrialization", In: T. Hewitt, H. Johnson and D. Wield (Eds.), Industrialization and Development, Oxford University Press.

Janssen, F. (2002). Do managers' characteristics influence the employment growth of SMEs? Journal of Small Business \& Entrepreneurship, 19(3), 293-315.

Kaiser, H. F. (1958). The varimax criterion for analytic rotation in factor analysis. Psychometrika, 23(3), $187-$ 200.

Kalleberg, A. L., \& Leicht, K. T. (1991). Gender and organizational performance: Determinants of small business survival and success. Academy of management journal, 34(1), 136-161.

Kayanula, D., \& Quartey, P. (2000). The policy environment for promoting small and medium-sized enterprises in Ghana and Malawi.

Kumar, M. S. (1985). Growth, acquisition activity and firm size: evidence from the United Kingdom. The Journal of Industrial Economics, 327-338.

Lee, J. (2001), "Education for technology readiness: Prospects for developing countries”, Journal of Human Development, 2(1), 115-151. 
McGoldrick, P. J., \& Thompson, M. G. (1992). The role of image in the attraction of the out-of-town centre. International Review of Retail, Distribution and Consumer Research, 2(1), 81-98.

Morse, E.A., Fowler, S.W., and Lawrence, T.B. (2007), "The impact of virtual embedness on new venture survival: Overcoming the liabilities of newness", Entrepreneurship Theory \& Practice, 139-159.

Mugenda, O. M. (1999). Research methods: Quantitative and qualitative approaches. African Centre for Technology Studies.

of 40 small firms in northern England", Department of Employment, Research paper no.

Olawale, F., \&Garwe, D. (2010). Obstacles to the growth of new SMEs in South Africa: A principle component analysis approach. African journal of business and management. Vol. 4 (5). PP 729738.

Onugu, B. A. N. (2005). Small and medium enterprises (SMEs) in Nigeria: Problems and prospects. St. Clements University, Nigeria (Unpublished Dissertation for a Doctor of Philosophy in Management Award).

Parker, R. L., Riopelle, R., \& Steel, W. F. (1995). Small enterprises adjusting to liberalization in five African countries (Vol. 271). World Bank Publications.

Pasanen, M. (2007). SME growth strategies: organic or non-organic?.Journal of Enterprising Culture, 15(04), 317-338.

Romijn, H. (2001). Technology support for small-scale industry in developing countries: a review of concepts and project practices. Oxford Development Studies, 29(1), 57-76.

Sarwoko, E., \& Frisdiantara, C. (2016). Growth Determinants of Small Medium Enterprises (SMEs). Universal Journal of Management, 4(1), 36-41.

Singh, R., Garg, S.\&Deshmukh, G.S. (2008) Strategy development by SMEs for competitiveness: A review. Bench-marking: an international journal. Vol.15 (5). PP 525-547

Storey, D. J. (1994). The role of legal status in influencing bank financing and new firm growth. applied economics, 26(2), 129-136.

Storey, D., Watson, R. and Wynarczyk, P. (1989), "Fast growth small businesses: case studies

Sutton, J. (1997). Gibrat's legacy. Journal of economic literature, 35(1), 40-59.

Thompson Agyapong, G., Mmieh, F., \& Mordi, C. (2018). Factors influencing the growth of SMEs: The case of Ghana. Thunderbird International Business Review, 60(4), 549-563.

Westhead, P. (1995). Exporting and non-exporting small firms in Great Britain: a matched pairs comparison. International Journal of Entrepreneurial Behavior \& Research, 1(2), 6-36.

Yusuf, et al. (2003), Innovative East Asia: The Future of Growth, Washington, D. C.: The World Bank, Copublication of the World Bank and Oxford University Press. 